\title{
Evaluation of whole wheat flour sourdough as a promising ingredient in short dough biscuits
}

\author{
Tuba ALIOĞLU1 ${ }^{1}$, Görkem ÖZÜLKÜ²* (b)
}

\begin{abstract}
The incorporation of whole wheat flour (WWF) via sourdough fermentation was studied in short dough biscuits. The substitution levels of wheat flour to WWF were $15 \%, 25 \%, 35 \%$, and 50\%. The biscuits containing WWF sourdough were produced by achieving the same level of WWF as in the WWF biscuits. The incorporation of WWF on dough formulation increased both G' and G" moduli, while the inclusion of WWF by sourdough fermentation caused a significant reduction. Spread ratio of the biscuits decreased as the WWF ratio in the formulation increased $(\mathrm{p}<0.05)$. The hardness value of WWF sourdough biscuits was not significantly different than that of the control biscuits while the direct addition of WWF increased the hardness value $(\mathrm{p}<0.05)$. Biscuits containing WWF sourdough had significantly higher lightness $\left(\mathrm{L}^{*}\right)$ value than the WWF biscuits $(\mathrm{p}<0.05)$. A low-level incorporation of sourdough corresponding to $15 \% \mathrm{WWF}$ was preferable by the panelists for general acceptability parameters.
\end{abstract}

Keywords: biscuit; whole wheat flour; sourdough fermentation; quality.

Practical Application: Whole grain consumption in the diet strongly recommended in recent years. Product diversity should be increased to make a significant contribution to daily intake of whole grains. Whole wheat flours (WWF) are one of the whole grains product and have been widely used in bakery industry. Some physical quality losses such as decreasing the spread ratio and increasing hardness value have been observed in the production of WWF biscuits. In this study, WWF was incorporated into biscuit by using sourdough fermentation in order to improve biscuit quality in terms of physical, textural and sensorial. This study also contributes to widen the product diversity of whole grain foods and provides insight of using sourdough as a promising indgredient in biscuit formulation.

\section{Introduction}

Sweet bakery products such as biscuits are considered as high energy snack foods and have been consumed by all age groups for years. Flour, sugar, and fat are the main ingredients of biscuits, and their low moisture content is a distinctive characteristic (Mancebo et al., 2018; Sudha et al., 2007).

Whole grain (WG) consists of three different anatomical components: endosperm, bran, and germ. All components together are healthier than any single part (Harvard Health Letter, 1999). Early epidemiological studies consistently showed that consuming more WGs reduced the risk of certain chronic diseases such as cardiovascular diseases, diabetes, and some cancers (Seal \& Brownlee, 2010). Some recommendations on WG consumption emphasized that at least half of all cereal servings should be WG-based (U.S. Department of Agriculture, Agriculture Research Service, 2000). Higher recommendations were established in Denmark and Sweden at $75 \mathrm{~g} / 2000 \mathrm{kcal}$ (Kyrø et al., 2012). Nevertheless, public consumption falls short of these targets (McMackin et al., 2013). Common preference for refined products, poor acceptance of WG foods, and the limit of a variety of WG products have been considered as the factors discouraging an increase in WG consumption (Adams \& Engstrom, 2000). Product diversity should be increased to make a significant contribution to daily WG intake (Whole Grains Council, 2012). Bakery products can play a role in helping consumers increase the WG content in a regular part of their diet. However, formulation of bakery products that contains sufficient amount of WG to offer health benefits, while maintaining a strong consumer appeal in terms of taste, texture, and color, presents considerable challenge for food designers (Schaffer-Lequart et al., 2017).

Whole wheat flour (WWF), containing the benefits of WGs, is widely used in the bakery industry to increase product diversity. WWF is richer than refined wheat flour since it has higher levels of vitamins, minerals, antioxidants, and fiber (Doblado-Maldonado et al., 2012). As a traditionally recognized product, bread is the main choice of food product for WWF incorporation. Healthy snacks, cakes, biscuits, and pasta are some of the products where WWF could be incorporated to broaden the spectrum of WG-containing food.

Sourdough fermentation, which is a traditional method of bread production, also provides novel insights for the production of other bakery products such as biscuits, crackers, and cakes (Sahin et al., 2019; Selimović et al., 2017). Formation of health-promoting components in food is attributed to sourdough 
fermentation through metabolic activities of specific microorganisms and inherent enzymes. Palatability and the textural property of WWF products are also improved via sourdough fermentation (Katina et al., 2007; Omoba \& Isah, 2018).

This study was designed to examine the use of WWF sourdough as an ingredient in biscuit formulation to improve the overall nutrition and texture quality. A comparison of WWF biscuits with WWF sourdough-incorporated biscuits was performed in order to evaluate the primary consumer prerequisites in terms of sensorial and textural quality.

\section{Materials and method}

\subsection{Materials}

Biscuit wheat flour and whole wheat flour (WWF) in this study were obtained commercially. The moisture, protein, and ash content of the biscuit flour was $12.8 \%, 9.58 \%$, and $0.67 \%$, respectively. The moisture protein, and ash content of the WWF was $10.40 \%, 11.14 \%$, and $1.34 \%$, respectively. Sugar powder, non-fat dry milk powder, brown sugar, sodium chloride, shortening, high fructose corn syrup (HFCS), sodium bicarbonate and ammonium bicarbonate were obtained from Ülker A.Ş. (Istanbul, Turkey).

\subsection{Sourdough preparation and biscuits formulation}

Control biscuits, biscuits containing WWF at different levels $(15 \%, 25 \%, 35 \%$, and $50 \%)$, and WWF sourdough biscuits were produced for this study according to wire-cut cookie formulation (American Association of Cereal Chemists, 1990). Some modifications in this formulation were carried out to compare the effect of WWF sourdough with the direct addition of WWF into biscuit formulation. Three formulations were designed for this aim and the details of the formulation are given below:

Formulation 1: $80 \mathrm{~g}$ of biscuit wheat flour, $32 \mathrm{~g}$ of shortening, $0.8 \mathrm{~g}$ of non-fat dry milk, $1 \mathrm{~g}$ of salt, $0.8 \mathrm{~g}$ of sodium bicarbonate, $0.4 \mathrm{~g}$ of ammonium bicarbonate, $25.60 \mathrm{~g}$ of sugar powder, $8 \mathrm{~g}$ of brown sugar, $1.2 \mathrm{~g}$ of HFCS. All ingredients were mixed according to the AACC Method 10-54 (American Association of Cereal Chemists, 1990). This formulation was considered as the control.

Formulation 2: $80 \mathrm{~g}$ flour was prepared by mixing wheat flour with WWF at the levels of 15\% (WWF15), 25\% (WWF25), $35 \%$ (WWF35), and 50\% (WWF50). Other ingredients as stated in formulation 1 were added and the biscuits were produced (American Association of Cereal Chemists, 1990)

Formulation 3: The biscuits containing WWF sourdough were produced in this formulation. The Type I sourdough protocol described by Ercolini et al. (2013) was used with some modifications to prepare WWF sourdough. The dough yield (dough yield = amount sourdough $\mathrm{X}$ 100 /amount of flour) of WWF sourdough was 180 and a refreshment procedure was performed by daily until the $\mathrm{pH}$ of sourdough reached a constant value $(\sim 3.90-3.93)$. WWF sourdough containing biscuits (WWFSD) were prepared to match the level of WWF in formulation 2: $20 \mathrm{~g}, 40 \mathrm{~g}, 60 \mathrm{~g}$, and $80 \mathrm{~g}$ WWF sourdough addition into formulation 3 corresponds with 15\%, 25\%,35\%, and 50\% WWF, respectively. The other ingredients were same as stated in formulation 1 and WWFSD 20, WWFSD 40, WWFSD 60, and WWFSD 80 biscuits were produced.

The amount of other ingredients (e.g. shortening, non-fat dry milk, salt) were at the same level in all formulations. The water content was variable to adjust the dough machinability.

For all biscuits, dough was rolled out to disks with $6 \mathrm{~cm}$ diameter and then baked at $185 \pm 2{ }^{\circ} \mathrm{C}$ for $15 \mathrm{~min}$ in the oven (Wiesheu, Minimat 43S, Germany).

\subsection{Rheological analyses of biscuits dough}

Dynamic rheological measurements of biscuit samples were performed at $25^{\circ} \mathrm{C}$ using a stress/strain-controlled rheometer (Anton Paar MCR 302, Australia) equipped with parallel plate configuration. The linear viscoelastic region (LVR) was determined between 0.1 and $100 \%$ strain values at $1 \mathrm{~Hz}$. The strain value of LVR was selected as $0.2 \%$ applied at the frequency sweep test. A frequency range of $0.1-30 \mathrm{~Hz}$ was used with a $2 \mathrm{~mm}$ gap. Storage modulus (G'), loss modulus (G”), and complex viscosity $\left(\eta^{\star}\right)$ were measured. The experimental data was described by using a power law model. Model parameters including intercepts (K', K”, and $\mathrm{K}^{\star}$ ) and slopes (n', n", and $n^{\star}$ ) were calculated according to the following Equations 1, 2 and 3 (Yoo \& Rao, 1996):

$G^{\prime}=K^{\prime}(\omega)^{n^{\prime}}$

$G^{\prime \prime}=K^{\prime \prime}(\omega)^{n "}$

$\eta^{*}=K^{*}(\omega)^{n^{*}-1}$

Tan $\delta$ values $\left(G^{\prime \prime} / G^{\prime}\right)$ were also calculated in order to determine the proportions of viscous and elastic parts in a dough system.

\subsection{Biscuit quality determination}

Spread ratio

Dimensions and thickness of biscuits were measured by using electronic caliper $(0.001 \mathrm{~mm}$, Mitutoyo, Tokyo, Japan). Spread ratio (SR) was determined by dividing the dimensions by thickness. Five biscuits were analyzed to calculate a mean value.

\section{Color measurement}

Minolta Chromameter (CR-100 Konica, Japan) was used to analyse the color of the biscuits. The color parameters, namely $\mathrm{L}^{*}$ (lightness), $\mathrm{a}^{*}$ (redness or greenness), and $\mathrm{b}^{*}$ (yellowness or blueness) were assessed by the CIE $\mathrm{L}^{\star} \mathrm{a}^{\star} \mathrm{b}^{\star}$ color system. 


\section{Textural analysis}

Textural characteristics of the biscuit samples were determined according to a three-point bend rig using texture profile analyzer (SMS TA.XT2 Plus, UK). The measurement was carried out with a force of $50 \mathrm{~N}$ and a test speed of $3 \mathrm{~mm} / \mathrm{s}$. Three biscuits for each type were analyzed for the means of the data.

\section{Sensory analysis}

Sensorial evaluation of the biscuit samples was performed by 22 panelists aged 18-45 years old. The sensory attributes was determined as taste, odor, color, appearance, crispness, and general acceptability using a hedonic scale from 0 to 9 (1: extremely dislike, 5: neither like nor dislike, 9: extremely like).

\section{Statistical analysis}

Experimental results were subjected to variance analysis (ANOVA) and the means were tested using Student's $t$ test at $\mathrm{p}<0.05$ using JMP ver.6 software (SAS Institute, Inc. 2005).

\section{Results and discussion}

\subsection{Rheological behavior of biscuit dough}

The effect of WWF and WWF sourdough incorporation on the dynamic rheological behavior of biscuit dough is shown in Figure 1. The power law model was used to describe experimental data and model parameters known as consistency coefficient ( $\left.\mathrm{K}^{\prime}, \mathrm{K}^{\prime}\right)$ and flow behavior index (n', n") were determined (Table 1). Typical viscoelastic properties were observed in all dough samples since the storage modulus ( $\left.G^{\prime}\right)$ was higher than the loss modulus (G”) (Figure 1). Addition of WWF to the dough formulation at $15 \%$ to $50 \%$ of the total flour increased both G' and G" moduli while WWF sourdough incorporation decreased it. As predicted from the raw data of G' and G" as a function of angular velocity, the values of $K^{\prime}$ were higher than those of $K^{\prime \prime}$, which was also exhibited by the solid viscoelastic character of all biscuit dough samples (Table 1). The range of $\mathrm{R}^{2}$ is 0.953-0.994 for G', 0.967-0.995 for G”, and 0.996-0.999 for complex viscosity $\left(\eta^{\star}\right)$, indicating a good correlation among experimental data. The solid character index (K') of the biscuits dough produced with high WWF addition (WF 35 and WF 50) reached the highest values in all. Tan $\delta$ is a parameter between 0 and 1 which represents the proportions of viscous and elastic parts in a dough system. Incorporation of the highest amount of WWF sourdough resulted in significantly higher Tan $\delta$ values in biscuits samples (WFSD 60 and WFSD 80) $(\mathrm{P}<0.05)$ (Figure 2). This result also indicated a higher viscous proportion in the dough system. Sahin et al. (2019) also observed that the increment of Tan $\delta$ value with the addition of $10 \%$ sourdough to sugar-reduced biscuits. The replacement of wheat flour by WWF in biscuit dough and low level of WWF sourdough addition (WFSD 20) lead to no significant differences in terms of Tan $\delta$ as compared to control sample (Figure 2). This may indicate that there are no structural changes in these samples since Tan $\delta$ value is also an indicator of the molecular interactions in a material (Ahmed, 2015). Resistant starch (RS) in short dough biscuits did also not change the viscoelastic properties as the Tan $\delta$ value was kept constant with the increasing level of RS (Laguna et al. 2013).

\subsection{Biscuit quality characteristics}

Sourdough fermentation is an acidification process. The influence of this acidity in dough may hydrolyze the gluten,

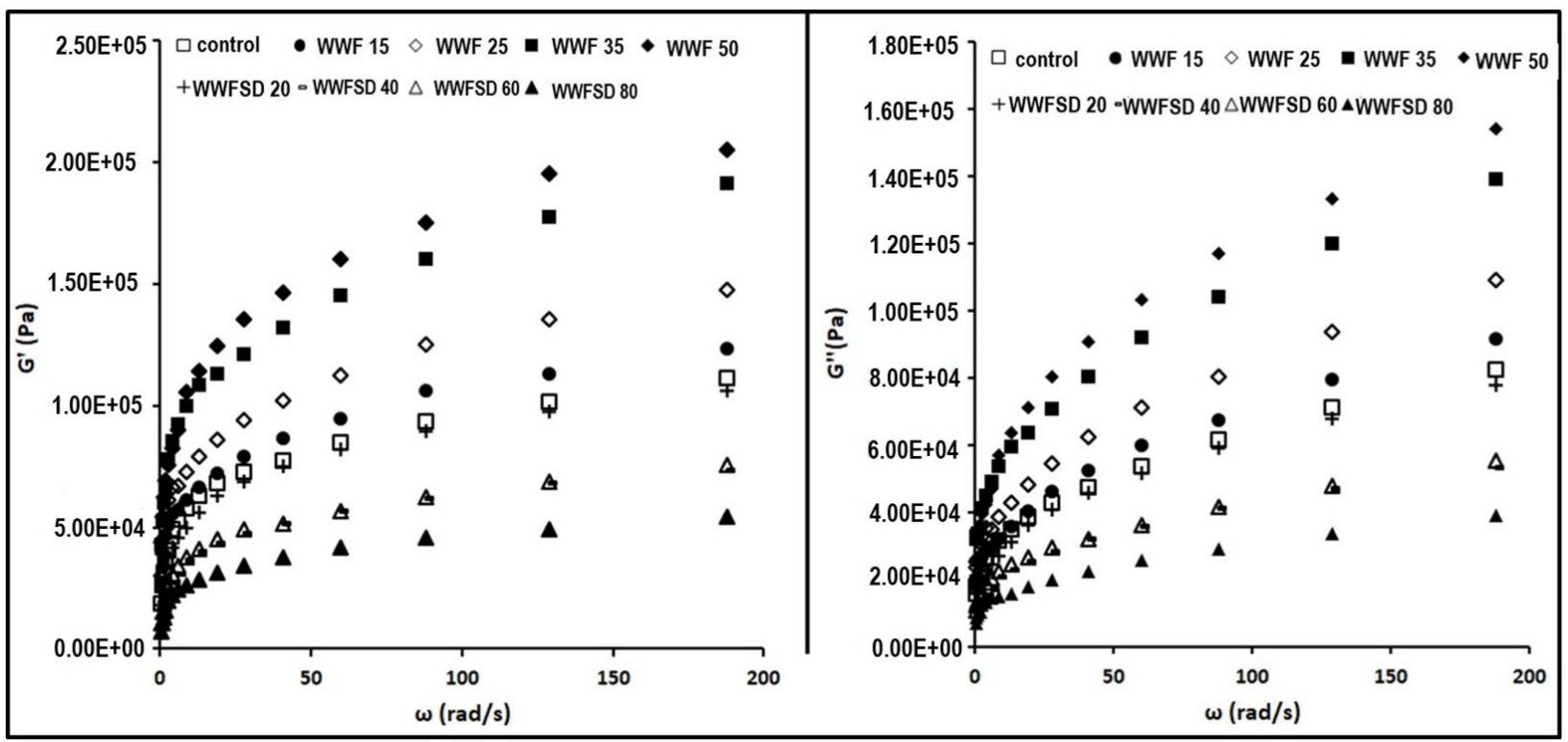

Figure 1. Dynamic rheological behavior of biscuit dough. WWF: Whole Wheat Flour; Control: Biscuit dough containing 0\% WWF, WWF15: Biscuit dough containing 15\% WWF, WWF 25: Biscuit dough containing 25\% WWF, WWF 35: Biscuit dough containing 35\% WWF, WWF 50: Biscuit dough containing 50\% WWF, WWFSD 20: Biscuit dough containing $20 \mathrm{~g}$ WWF sourdough, WWFSD 40: Biscuit dough containing $40 \mathrm{~g}$ WWF sourdough, WWFSD 60: Biscuit dough containing $60 \mathrm{~g}$ WWF sourdough, WWFSD 80: Biscuit dough containing $80 \mathrm{~g}$ WWF sourdough. 
Table 1. Dynamic rheological properties of biscuit samples.

\begin{tabular}{|c|c|c|c|c|c|c|c|c|c|}
\hline & \multicolumn{3}{|c|}{$\mathrm{G}^{\prime}=\mathrm{K}^{\prime}(\omega)^{\mathrm{n}^{\prime}}$} & \multicolumn{3}{|c|}{$\mathrm{G}^{\prime \prime}=\mathrm{K}^{\prime \prime}(\omega)^{\mathrm{n}^{\prime \prime}}$} & \multicolumn{3}{|c|}{$\eta^{*}=K^{*}(\omega)^{n^{*}-1}$} \\
\hline & $\mathrm{K}^{\prime}(\mathrm{Pa})$ & $\mathrm{n}^{\prime}$ & $\mathrm{R}^{2}$ & $\mathrm{~K}^{\prime \prime}(\mathrm{Pa})$ & $\mathrm{n}^{\prime \prime}$ & $\mathrm{R}^{2}$ & $\mathrm{~K}^{\star}(\mathrm{Pa} . \mathrm{s})$ & $\mathrm{n}^{*}$ & $\mathrm{R}^{2}$ \\
\hline Control & $28899 \pm 808.9^{d}$ & $0.262 \pm 0.021^{\mathrm{bc}}$ & 0.975 & $17325 \pm 17^{\mathrm{c}}$ & $0.2732 \pm 0.0126^{b c}$ & 0.967 & $33848.5 \pm 654.1^{\mathrm{cd}}$ & $0.275 \pm 0.0042^{c}$ & 0.999 \\
\hline WWF 25 & $50807 \pm 1609.4^{\mathrm{b}}$ & $0.2479 \pm 0.0016^{c}$ & 0.975 & $26956 \pm 3743.4^{\mathrm{b}}$ & $0.2666 \pm 0.0085^{b c}$ & 0.980 & $54210 \pm 8107.7^{\mathrm{b}}$ & $0.248 \pm 0.0014^{\mathrm{d}}$ & 0.999 \\
\hline WWF 35 & $54201 \pm 1783.3^{\mathrm{a}}$ & $0.2424 \pm 0.0011^{\mathrm{c}}$ & 0.988 & $29271.5 \pm 3121.9^{\mathrm{ab}}$ & $0.26 \pm 0.0028^{\mathrm{bc}}$ & 0.971 & $59184.5 \pm 6820^{\mathrm{ab}}$ & $0.248 \pm 0^{\mathrm{d}}$ & 0.999 \\
\hline WWFSD 40 & $16741.5 \pm 577.7^{\mathrm{f}}$ & $0.3049 \pm 0.0042^{\mathrm{a}}$ & 0.969 & $11104.5 \pm 249.6^{\mathrm{e}}$ & $0.2906 \pm 0.0013^{\mathrm{a}}$ & 0.992 & $30836.5 \pm 1426.2^{\mathrm{de}}$ & $0.301 \pm 0^{\mathrm{a}}$ & 0.999 \\
\hline WWFSD 60 & $17072.5 \pm 473.1^{\mathrm{f}}$ & $0.2997 \pm 0.0127^{a}$ & 0.953 & $12149.5 \pm 241.1^{\mathrm{e}}$ & $0.2698 \pm 0.0032^{\mathrm{bc}}$ & 0.988 & $21160.5 \pm 211.4^{\mathrm{f}}$ & $0.288 \pm 0.0085^{\mathrm{b}}$ & 0.996 \\
\hline WWFSD 80 & $18374 \pm 461^{\mathrm{f}}$ & $0.3037 \pm 0.0066^{\mathrm{a}}$ & 0.961 & $13153 \pm 1073.4^{\mathrm{de}}$ & $0.2742 \pm 0.0069^{\mathrm{bc}}$ & 0.995 & $22776 \pm 1023.9^{\text {ef }}$ & $0.2925 \pm 0.0064^{\mathrm{ab}}$ & 0.997 \\
\hline
\end{tabular}

Means with a same letter within a column are not significantly different ( $\mathrm{p} \leq 0.05)$; WWF: Whole Wheat Flour; Control: Biscuit dough containing 0\% WWF, WWF15: Biscuit dough containing 15\% WWF, WWF 25: Biscuit dough containing 25\% WWF, WWF 35: Biscuit dough containing 35\% WWF, WWF 50: Biscuit dough containing 50\% WWF, WWFSD 20: Biscuit dough containing $20 \mathrm{~g}$ WWF sourdough, WWFSD 40: Biscuit dough containing $40 \mathrm{~g}$ WWF sourdough, WWFSD 60: Biscuit dough containing 60 g WWF sourdough, WWFSD 80: Biscuit dough containing $80 \mathrm{~g}$ WWF sourdough.

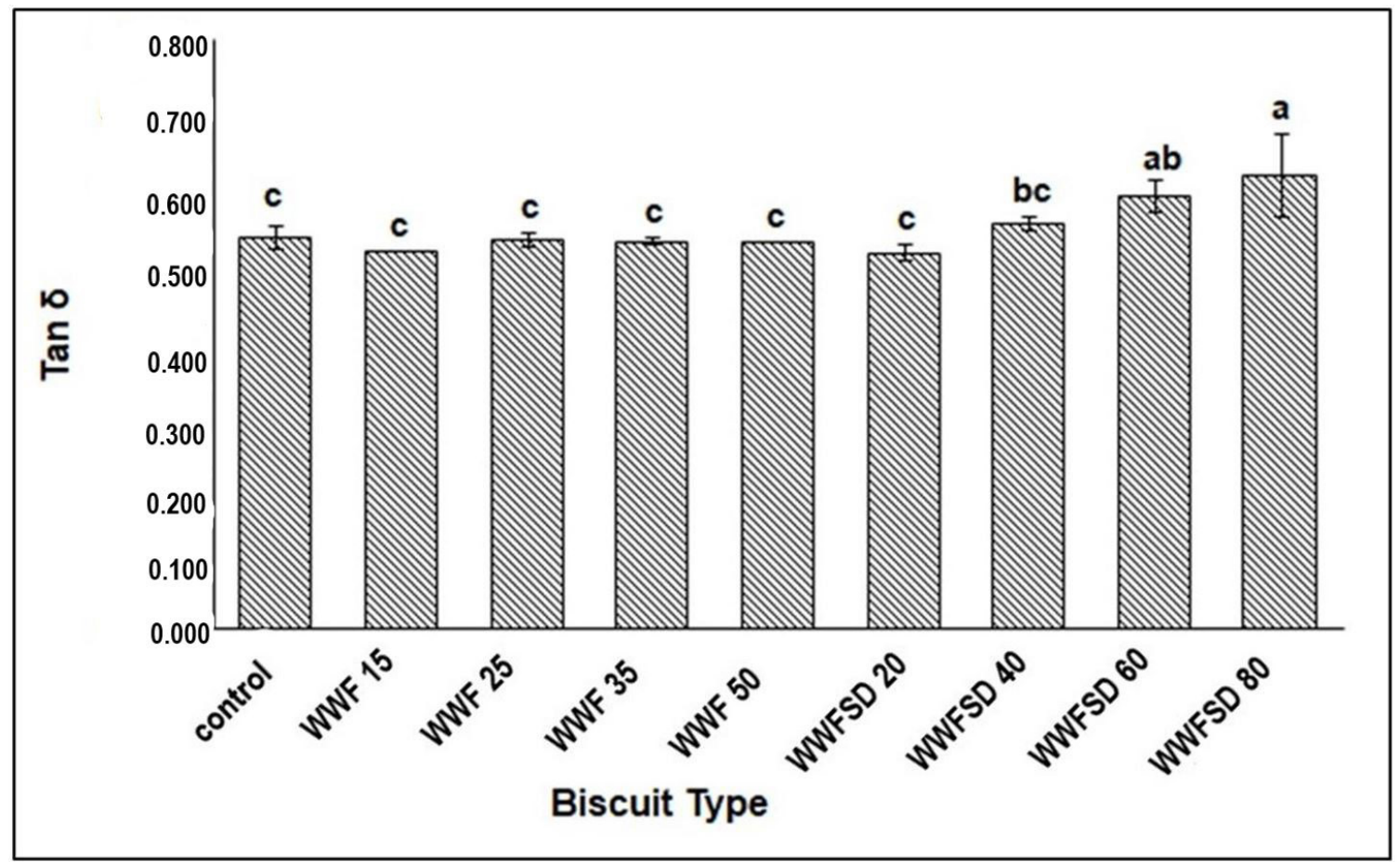

Figure 2. Tan $\delta$ values of biscuit samples. WWF: Whole Wheat Flour; Control: Biscuit dough containing 0\% WWF, WWF15: Biscuit dough containing 15\% WWF; WWF 25: Biscuit dough containing 25\% WWF, WWF 35: Biscuit dough containing 35\% WWF; WWF 50: Biscuit dough containing 50\% WWF, WWFSD 20: Biscuit dough containing $20 \mathrm{~g}$ WWF sourdough,WWFSD 40: Biscuit dough containing $40 \mathrm{~g}$ WWF sourdough, WWFSD 60: Biscuit dough containing $60 \mathrm{~g}$ WWF sourdough, WWFSD 80: Biscuit dough containing $80 \mathrm{~g}$ WWF sourdough. The samples having same letter are not significantly different $(\mathrm{p}>0.05)$

starch, and arabinoxylans found in cereal flour. Another impact of acidification is the activity of cereal enzymes such as proteases. Proteolytic activity and low $\mathrm{pH}$ contribute some physical changes on dough characteristics since increasing the solubility of structure-forming components (Arendt et al., 2007). The effect of WWF and WWF sourdough incorporation on spread factor, hardness and color properties of biscuits samples were shown in Table 2.

\subsection{Spread ratio}

Spread ratio, which expresses the shape characteristics of the biscuits, is considered as a complex phenomenon influenced by variety of factors. Biscuits with a higher spread ratio are generally regarded as desirable (Suriya et al., 2017). The highest spread ratio was observed for control biscuits (Table 2). The replacement of wheat flour with WWF from $25 \%$ 
Table 2. Physical properties of biscuits.

\begin{tabular}{|c|c|c|c|c|c|}
\hline Sample name & Spread Factor & Hardness (N) & $L^{*}$ & $a^{*}$ & $b^{*}$ \\
\hline Control & $0.75 \pm 0.01^{a}$ & $24.8 \pm 0.92^{c}$ & $62.66 \pm 048^{b}$ & $5.58 \pm 0.36^{\mathrm{d}}$ & $31.12 \pm 0.89^{\mathrm{a}}$ \\
\hline WWF15 & $0.72 \pm 0.01^{\mathrm{ab}}$ & $30.02 \pm 0.50^{\mathrm{b}}$ & $61.89 \pm 0.51^{\mathrm{b}}$ & $7.77 \pm 0.34^{\mathrm{b}}$ & $30.10 \pm 0.64^{\mathrm{ab}}$ \\
\hline WWF 35 & $0.68 \pm 0.01^{\mathrm{cd}}$ & $31.05 \pm 0.29^{b}$ & $56.13 \pm 0.86^{\mathrm{d}}$ & $8.39 \pm 0.27^{\mathrm{a}}$ & $29.19 \pm 0.43^{b}$ \\
\hline WWF 50 & $0.67 \pm 0.01^{\mathrm{d}}$ & $33.06 \pm 0.36^{\mathrm{a}}$ & $55.29 \pm 0.11^{\mathrm{d}}$ & $8.72 \pm 0.40^{\mathrm{a}}$ & $29.02 \pm 0.20^{b}$ \\
\hline WWFSD 40 & $0.71 \pm 0.01^{\mathrm{cd}}$ & $24.14 \pm 1.10^{c}$ & $61.74 \pm 0.16^{b c}$ & $7.52 \pm 0.30^{\mathrm{b}}$ & $31.30 \pm 0.53^{\mathrm{a}}$ \\
\hline WWFSD 60 & $0.67 \pm 0.03^{\text {cd }}$ & $21.16 \pm 1.83^{\mathrm{d}}$ & $65.99 \pm 1.73^{\mathrm{a}}$ & $5.42 \pm 0.28^{\mathrm{d}}$ & $29.02 \pm 1.01^{b}$ \\
\hline WWFSD 80 & $0.58 \pm 0.02^{\mathrm{e}}$ & $24.85 \pm 1.09^{c}$ & $66.52 \pm 0.63^{\mathrm{a}}$ & $3.69 \pm 0.11^{\mathrm{e}}$ & $26.19 \pm 0.30^{c}$ \\
\hline
\end{tabular}

Means with a same letter within a column are not significantly different ( $\mathrm{p} \leq 0.05)$; WWF: Whole Wheat Flour; Control: Biscuit dough containing 0\% WWF, WWF15: Biscuit dough containing 15\% WWF, WWF 25: Biscuit dough containing 25\% WWF, WWF 35: Biscuit dough containing 35\% WWF, WWF 50: Biscuit dough containing 50\% WWF, WWFSD 20: Biscuit dough containing $20 \mathrm{~g}$ WWF sourdough, WWFSD 40: Biscuit dough containing $40 \mathrm{~g}$ WWF sourdough, WWFSD 60: Biscuit dough containing 60 g WWF sourdough, WWFSD 80: Biscuit dough containing $80 \mathrm{~g}$ WWF sourdough.

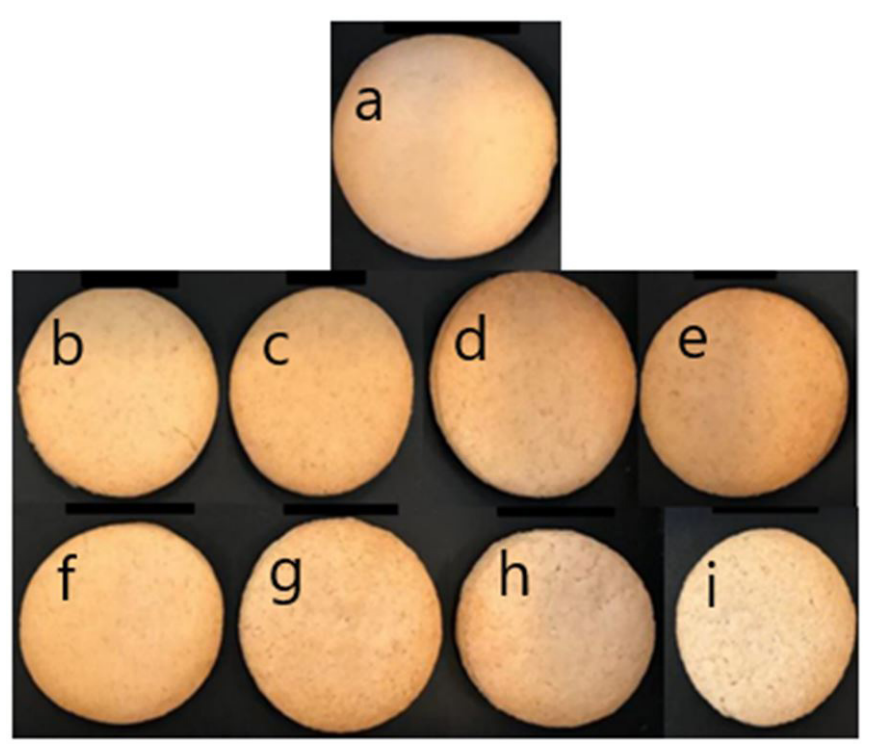

Figure 3. Images of biscuit samples. (a) Control, (b) WWF 15, (c) WWF 25, (d) WWF 35, (e) WWF 50, (f) WWFSD 20, (g) WWFSD 40, (h) WWFSD 60, (i) WWFSD 80 WWF: Whole Wheat Flour; WWF 15: Biscuit dough containing 15\% WWF; WWF 25: Biscuit dough containing 25\% WWF; WWF 35: Biscuit dough containing 35\% WWF; WWF 50: Biscuit dough containing 50\% WWF; WWFSD 20: Biscuit dough containing $20 \mathrm{~g}$ WWF sourdough; WWFSD 40: Biscuit dough containing $40 \mathrm{~g}$ WWF sourdough; WWFSD 60: Biscuit dough containing $60 \mathrm{~g}$ WWF sourdough; WWFSD 80: Biscuit dough containing $80 \mathrm{~g}$ WWF sourdough.

to $50 \%$ addition level (WWF 25 -WWF 50 ) caused a significant reduction in the spread ratio of the biscuits as compared to control (Table 2). This aligns with the results of Demir (2015) who studied the replacement level of wheat flour from $20 \%$ to $100 \%$ with WWF. A similar observation was reported for wheat bran incorporation into biscuit formulation (Sudha et al., 2007). The thickness of biscuits was more affected than the biscuit diameter by the inclusion of WWF in the formulation (Table 2).
Incorporation of WWF sourdough into biscuits did not modify spread factor. This effect could be attributed to leavening capability of sourdough in the biscuit in conjunction with the other leavening agents in formulation. This was also pointed out by Olapade \& Adeyemo (2014), who suggested that the lowest spread ratio indicated better rising ability of biscuits. A high level of WWF sourdough addition (WFSD 80) decreased the spread ratio of biscuits further as compared to other applications ( $\mathrm{p}<0.05$, Table 2). Similarly, biscuit dough matrix containing high protease activity wholemeal flour caused a significant reduction in spread ratio as observed in an earlier study by Kara et al. (2005). Contrary to these results, Sahin et al. (2019) reported that up to $10 \%$ sourdough addition improved the spreading process for low-sugar biscuits. Bravo-Nuñez et al. (2018) performed a study with gluten (GP) and hydrolyzed gluten proteins (HGP) to investigate cookie characteristics. The authors demonstrated that the addition of HGP increased the spread ratio of cookies due to the lower rheology values ( $G$ ' and G") of HGP doughs. The improvement of WWF sourdough addition to biscuits was not detected for spread ratio in the present study. This could be due to matrix differences used in the biscuit formulations.

\subsection{Texture}

Addition of WWF to biscuit dough increased the hardness value compared to the control while the biscuits containing WWF sourdough had values close to control (Table 2). WWF incorporation from WWF 15 to WWF 35 lead to no significant change in the hardness value. A noticeable effect was observed in biscuit containing high level WWF (WWF 50) $(\mathrm{p}<0.05)$. Demir (2015) also recorded increased hardness with an increasing level of WWF in biscuits. Similar effects were reported for dietary fiber incorporation into biscuits. Mancebo et al. (2018) indicated that biscuits enriched with fiber became harder, but differences were more observable in the case of insoluble fiber addition. A decrease in biscuit hardness was observed for WWF incorporation to biscuits via sourdough fermentation as compared to direct addition 
of WWF. It may be that the amount of water in the sourdough biscuits is variable due to some technological constraints. A greater amount of water in the sourdough biscuit formulations caused more water to remain in the structure after baking, thus reducing the hardness of the biscuit, which is not different from the control. Secondly, hydrolysis of gluten proteins during sourdough fermentation may lead to a decrease the hardness of biscuits. These results were in agreement with the results of Bravo-Nuñez et al. (2018) which indicated that hydrolyzed gluten proteins incorporation decreased the hardness of biscuits.
In the study of Sahin et al. (2019), 10\% sourdough addition to sugar-reduced biscuit dough decreased the dough hardness and increased biscuits firmness. Sahin et al. (2019) clarified this effect by the fact that starch hydrolysis by the inclusion of acids in the biscuit dough caused the release of bond water. Decreasing the amount of bond water contributes to the formation of new bonds between carbohydrates, denatured proteins, protein subunits, and/or free amino acids from the sourdough. Fermentation of millet flour also caused an increase of hardness of millet biscuits (Adebiyi et al., 2016).
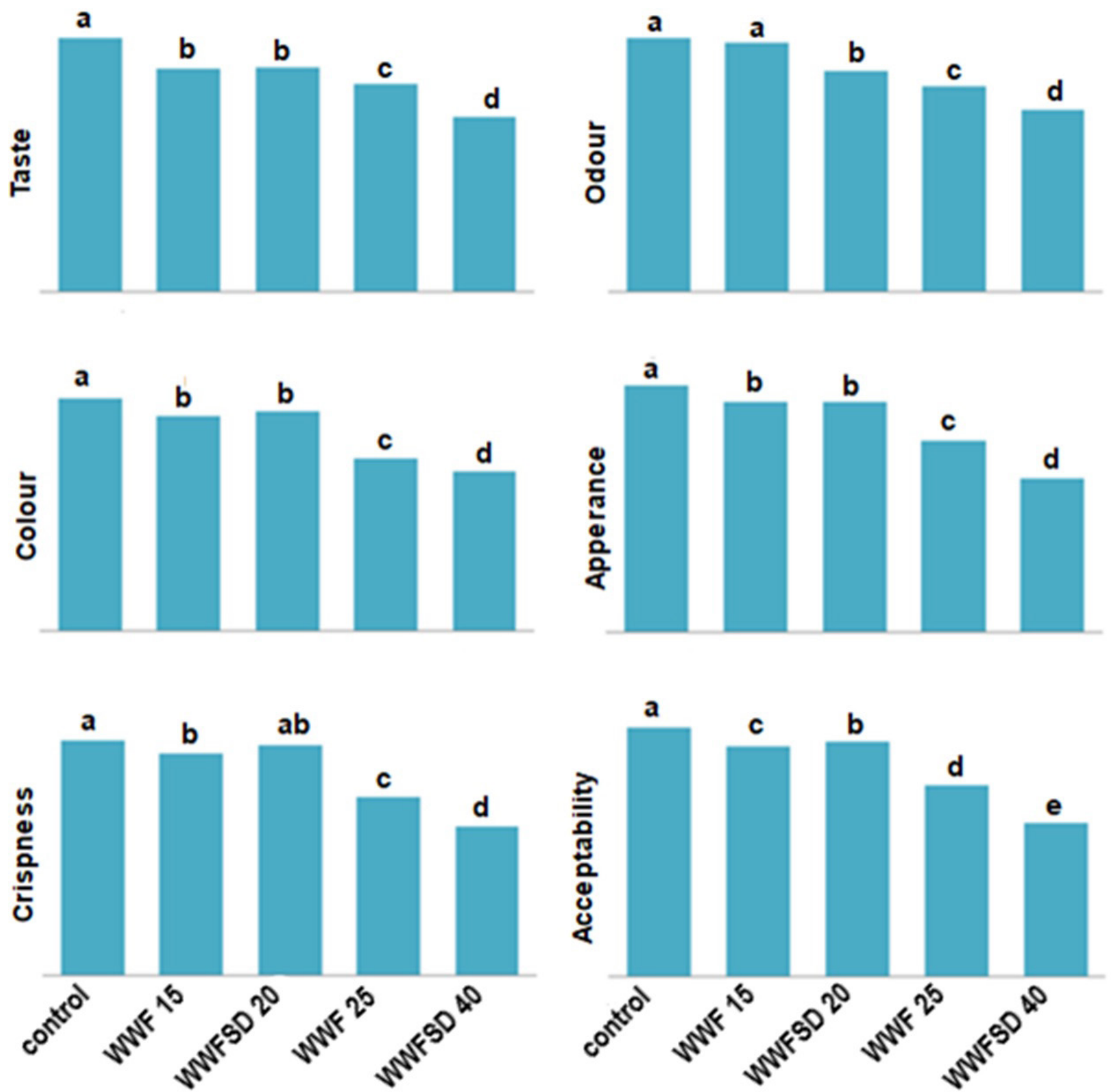

Figure 4. Sensorial characteristics of biscuit samples. WWF: Whole Wheat Flour; Control: Biscuit dough containing 0\% WWF; WWF 15: Biscuit dough containing 15\% WWF; WWF 25: Biscuit dough containing 25\% WWF; WWFSD 20: Biscuit dough containing 20 g WWF sourdough; WWFSD 40: Biscuit dough containing $40 \mathrm{~g}$ WWF sourdough. The samples having same letter are not significantly different ( $\mathrm{p}>0.05)$ 
Adebiyi et al. (2016) associated this increase with the better interaction of proteins and starch through hydrogen bonding. In this study, relatively low hardness values were obtained from WWF sourdough biscuits when compared to other studies performed with fermented millet flour and sourdough usage in sugar reduced biscuit formulations (Adebiyi et al., 2016; Sahin et al., 2019).

\subsection{Color}

Another important criterion for consumer acceptability in biscuits is color (Table 2). Incorporation of WWF cause a reduction of lightness $\left(\mathrm{L}^{*}\right)$ of the biscuits with the increasing level of WWF from $25 \%$ to $50 \%(\mathrm{p}<0.05)$. In a study performed by Bravo-Nuñez et al. (2018), hydrolyzed gluten proteins caused also reduction of $L^{*}$ value. This effect producing darker biscuits (lower $L^{*}$ ) improved with the addition of WWF via sourdough fermentation in the present study. Biscuits containing WWF sourdough (WWFSD) had significantly higher $\mathrm{L}^{*}$ value $(\mathrm{p}<0.05)$. This can be also attributed to the thickness of the WWFSD biscuits being higher (Table 2). Bravo-Nuñez et al. (2018) explained this phenomena that thickness of the biscuits could affect color properties because of the moisture losses kinetics and therefore, Maillard reactions. Sahin et al. (2019) found reduced color difference in sourdough biscuits as compared to control. Redness value $\left(\mathrm{a}^{\star}\right)$ of the biscuits containing WWF increased while $b^{*}$ value of WWF biscuits decreased significantly in the biscuits containing WWF as compared to the control (Table 2). However, a clear trend was not observed with an increase in the level of WWF. Similar results were observed for chickpea addition (Mieszkowska \& Marzec, 2016) and nutriose and polydextrose incorporation (Mancebo et al., 2018) into short dough biscuits.

\subsection{Sensorial evaluation of biscuits}

Figure 3 shows images of all the biscuits examined in the present study. A low level of WWF and WWF sourdough containing biscuits were selected for sensorial evaluation, namely WWF 15, WWF 25, WWFSD 20, WWFSD 40, since they were close to control in terms of some physical characteristics. Sensory analyses showed differences in biscuits taste, odor, color, appearance, crispness, and general acceptability attributes, where the control biscuit achieved highest scores in all (Figure 4). Highest scores were closely followed by WWF 15 and WWFSD 20, except for the general acceptability value of WWF 15 . Regarding taste, color, appearance, and crispness, no statistical differences were observed for WWF 15 and WWFSD 20. WWF 15 presented lower general acceptability value than WWFSD 20 ( p < 0.05), which shows that the incorporation of sourdough was preferable by the panelists. Higher addition of WWF and WWF sourdough (WWF 25 and WWFSD 40) caused lowest sensorial results in all parameters. Addition of hydrolyzed gluten proteins at 30 and $45 \%$ also presented significantly lower taste value in the study of Bravo-Nuñez et al. (2018) due to the formation of bitter compounds during Maillard reactions. Sourdough fermentation produces some aromatic compounds which are not favorable for biscuits and caused a significant reduction for WWFSD 40 sample in terms of taste attribute. Incorporation of sourdough at the level of 5 and $10 \%$ was previously performed by Sahin et al. (2019) for sugar reduced biscuits and sourdough containing fructose achieved the highest flavor intensity in all sourdough-biscuits.

\section{Conclusions}

WWF addition influenced the dough rheological properties, biscuit quality, and sensorial characteristics. It was evident that the extent of the effects was highly dependent on the level of WWF and WWF sourdough addition. Although WWF was added at almost the same level in both types of biscuits (WWF and WWFSD), the effect on biscuit quality was different. The addition of WWF via sourdough fermentation modified the texture and color characteristics of the biscuits while direct WWF addition caused some quality loss. A low level of WWF sourdough addition resulted in higher consumer acceptability than the direct addition of WWF into the biscuits. Additionally, no significant changes were observed in the rheological properties of the biscuits with the low level addition, which is an important parameter for large-scale production. This study also informs the consumer's daily intake of whole grain products as recommended by some dietary guidelines and provides some valuable insights into the use of sourdough as a promising ingredient in biscuit formulation.

\section{References}

Adams, J. F., \& Engstrom, A. (2000). Helping consumers achieve recommended intakes of whole grain foods. Journal of the American College of Nutrition, 19(suppl 3), 339S-344S. http://dx.doi.org/10.1 080/07315724.2000.10718970.

Adebiyi, J. A., Obadina, A. O., Mulaba-Bafubiandi, A. F., Adebo, O. A., \& Kayitesi, E. (2016). Effect of fermentation and malting on the microstructure and selected physicochemical properties of pearl millet (Pennisetum glaucum) flour and biscuit. Journal of Cereal Science, 70, 132-139. http://dx.doi.org/10.1016/j. jcs.2016.05.026.

Ahmed, J. (2015). Effect of barley $\beta$-glucan concentrate on oscillatory and creep behavior of composite wheat flour dough. Journal of Food Engineering, 152, 85-94. http://dx.doi.org/10.1016/j.jfoodeng.2014.11.018.

American Association of Cereal Chemists - AACC. (1990). American Association of Cereal Chemists, approved methods of the AACC (8th ed.). St. Paul, MN: AACC.

Arendt, E. K., Ryan, L. A., \& Dal Bello, F. (2007). Impact of sourdough on the texture of bread. Food Microbiology, 24(2), 165-174. http:// dx.doi.org/10.1016/j.fm.2006.07.011. PMid:17008161.

Bravo-Nuñez, Á., Sahagún, M., Martínez, P., \& Gómez, M. (2018). Incorporation of gluten and hydrolysed gluten proteins has different effects on dough rheology and cookie characteristics. International Journal of Food Science \& Technology, 53(6), 1452-1458. http:// dx.doi.org/10.1111/ijfs.13724.

Demir, M. K. (2015). Utilization of whole wheat flour and its blends in cookies production. Journal of Agricultural Sciences, 21, 100-107.

Doblado-Maldonado, A. F., Pike, O. A., Sweley, J. C., \& Rose, D. J. (2012). Key issues and challenges in whole wheat flour milling 
and storage. Journal of Cereal Science, 56(2), 119-126. http://dx.doi. org/10.1016/j.jcs.2012.02.015.

Ercolini, D., Pontonio, E., De Filippis, F., Minervini, F., La Storia, A., Gobbetti, M., \& Di Cagno, R. (2013). Microbial ecology dynamics during rye and wheat sourdough preparation. Applied and Environmental Microbiology, 79(24), 7827-7836. http://dx.doi. org/10.1128/AEM.02955-13. PMid:24096427.

Harvard Health Letter. (1999). The whole is greater than the sum of the parts. I. Whole grain. Harvard Health Letters, 25(1):8.

Kara, M., Sivri, D., \& Köksel, H. (2005). Effects of high proteaseactivity flours and commercial proteases on cookie quality. Food Research International, 38(5), 479-486. http://dx.doi.org/10.1016/j. foodres.2004.09.012.

Katina, K., Laitila, A., Juvonen, R., Liukkonen, K. H., Kariluoto, S., Piironen, V., Landberg, R., Aman, P., \& Poutanen, K. (2007). Bran fermentation as a means to enhance technological properties and bioactivity of rye. Food Microbiology, 24(2), 175-186. http://dx.doi. org/10.1016/j.fm.2006.07.012. PMid:17008162.

Kyrø, C., Skeie, G., Dragsted, L. O., Christensen, J., Overvad, K., Hallmans, G., Johansson, I., Lund, E., Slimani, N., Johnsen, N. F., Halkjær, J., Tjønneland, A., \& Olsen, A. (2012). Intake of whole grain in Scandinavia: Intake, sources and compliance with new national recommendations. Scandinavian Journal of Public Health, 40(1), 7684. http://dx.doi.org/10.1177/1403494811421057. PMid:21976053.

Laguna, L., Hernández, M. J., Salvador, A., \& Sanz, T. (2013). Study on resistant starch functionality in short dough biscuits by oscillatory and creep and recovery tests. Food and Bioprocess Technology, 6(5), 1312-1320. http://dx.doi.org/10.1007/s11947-012-0785-x.

Mancebo, C. M., Rodríguez, P., Martínez, M. M., \& Gómez, M. (2018). Effect of the addition of soluble (nutriose, inulin and polydextrose) and insoluble (bamboo, potato and pea) fibres on the quality of sugar snap cookies. International Journal of Food Science \& Technology, 53(1), 129-136. http://dx.doi.org/10.1111/ijfs.13566.

McMackin, E., Dean, M., Woodside, J. V., \& McKinley, M. C. (2013). Whole grains and health: attitudes to whole grains against a prevailing background of increased marketing and promotion. Public Health Nutrition, 16(4), 743-751. http://dx.doi.org/10.1017/ S1368980012003205. PMid:23102407.

Mieszkowska, A., \& Marzec, A. (2016). Effect of polydextrose and inulin on texture and consumer preference of short-dough biscuits with chickpea flour. $L W T, 73,60-66$. http://dx.doi.org/10.1016/j. lwt.2016.05.036.

Olapade, A. A., \& Adeyemo, M. A. (2014). Evaluation of cookies produced from blends of wheat, cassava and cowpea flours. International Journal of Food Studies, 3(2), 175-185. http://dx.doi.org/10.7455/ ijfs.v3i2.213.
Omoba, O. S., \& Isah, L. R. (2018). Influence of sourdough fermentation on amino acids composition, phenolic profile, and antioxidant properties of sorghum biscuits. Preventive Nutrition and Food Science, 23(3), 220-227. http://dx.doi.org/10.3746/pnf.2018.23.3.220. PMid:30386750.

Sahin, A. W., Rice, T., Zannini, E., Lynch, K. M., Coffey, A., \& Arendt, E. K. (2019). The incorporation of sourdough in sugar-reduced biscuits: a promising strategy to improve techno-functional and sensory properties. European Food Research and Technology, 245(9), 1841-1854. http://dx.doi.org/10.1007/s00217-019-03302-3.

Schaffer-Lequart, C., Lehmann, U., Ross, A. B., Roger, O., Eldridge, A. L., Ananta, E., Bietry, M. F., King, L. R., Moroni, A. V., Srichuwong, S., Wavreille, A. S., Redgwell, R., Labat, E., \& Robin, F. (2017). Whole grain in manufactured foods: current use, challenges and the way forward. Critical Reviews in Food Science and Nutrition, 57(8), 1562-1568. http://dx.doi.org/10.1080/10408398.2013.7810 12. PMid:25747755.

Seal, C. J., \& Brownlee, I. A. (2010). Whole grains and health, evidence from observational and intervention studies. Cereal Chemistry, 87(2), 167-174. http://dx.doi.org/10.1094/CCHEM-87-2-0167.

Selimović, A., Miličević, D., Selimović, A., Žuljević, S. O., Jašića, A., \& Vranac, A. (2017). Properties of crackers with buckwheat sourdough. Acta Chimica Slovenica, 10(2), 152-158. http://dx.doi. org/10.1515/acs-2017-0025.

Sudha, M. L., Vetrimani, R., \& Leelavathi, K. (2007). Influence of fibre from different cereals on the rheological characteristics of wheat flour dough and on biscuit quality. Food Chemistry, 100(4), 13651370. http://dx.doi.org/10.1016/j.foodchem.2005.12.013.

Suriya, M., Rajput, R., Reddy, C. K., Haripriya, S., \& Bashir, M. (2017). Functional and physicochemical characteristics of cookies prepared from Amorphophallus paeoniifolius flour. Journal of Food Science and Technology, 54(7), 2156-2165. http://dx.doi.org/10.1007/s13197017-2656-y. PMid:28720973.

U.S. Department of Agriculture, Agriculture Research Service. (2000). Report of the Dietary Guidelines Advisory Committeeon the Dietary Guidelines for Americans, 2000, to the Secretary of Health and Human Services and the Secretary of Agriculture. Maryland: U.S. Department of Agriculture, Agriculture Research Service.

Whole Grains Council. (2012). Whole grain stamp. Boston: Whole Grains Council. Retrieved from http://www.whole grainscouncil. org/whole-grain-stamp

Yoo, B., \& Rao, M. A. (1996). Creep and dynamic rheological behavior of tomato concentrates: effect of concentration and finisher screen size. Journal of Texture Studies, 27(4), 451-459. http://dx.doi. org/10.1111/j.1745-4603.1996.tb00087.x. 